\title{
ARTICLE OPEN Cetylpyridinium chloride produces increased zeta-potential on Salmonella Typhimurium cells, a mechanism of the pathogen's inactivation
}

\author{
Yagmur Yegin ${ }^{1}$, Jun K. Oh (iD ${ }^{2,4}$, Mustafa Akbulut ${ }^{2}$ and Thomas Taylor (iD ${ }^{3}$
}

Cetylpyridinium chloride (CPC) is a quaternary ammonium sanitizer approved for fresh poultry animal carcass sanitization from microbial human pathogens, such as Salmonella enterica. Nonetheless, the interactions of CPC with Salmonella cells, and the mechanism of the sanitizer's neutralization by lecithin remains largely unknown. This study aimed to investigate the interaction of CPC with lecithin and Salmonella Typhimurium to determine the interactions of the sanitizer and neutralizer impacting the bacterium's survival. Application of $0.8 \%$ CPC is proposed to produce loss of microbial membrane integrity with loss of electrostatic repulsion between individual cells, resulting in the eventual emulsification of membrane lipids with cytoplasmic contents leakage. Our findings point to a two-phase interaction between CPC and lecithin impacting S. Typhimurium survival. The first consists of electrostatic attraction and charge neutralization between oppositely charged components of pathogen cell and CPC. The second involves formation of aggregates between sanitizer and pathogen, or between sanitizer, pathogen membrane lipids, and lecithin.

npj Science of Food (2019)3:21

; https://doi.org/10.1038/s41538-019-0052-x

\section{INTRODUCTION}

In the United States, the manufacture of fresh poultry products is regulated by the U.S. Department of Agriculture Food Safety and Inspection Service (USDA-FSIS). For poultry carcasses and fresh cut pieces, multiple chemical sanitizers are approved to decontaminate eviscerated carcasses and pieces from microbial foodborne pathogens, including Salmonella enterica. ${ }^{1}$ The quaternary ammonium sanitizer cetylpyridinium chloride (CPC) has been repeatedly studied and reported effective for the sanitization of poultry carcass and meat surfaces from microbial pathogens at up to $0.8 \% .^{2-4}$ Recent research has indicated that carryover of some sanitizers into poultry carcass sampling rinse fluids may prevent the successful detection of pathogenic microbes during routine verification testing. ${ }^{5,6}$ Consequently, recent changes to routine testing methods for poultry carcass testing to detect microbial pathogens have raised questions about the utility and necessity of chemical sanitizer neutralizing agents (i.e., neutralizers) and their impact on poultry processors' ability to adhere to federal food safety performance standards for fresh poultry products. ${ }^{7,8}$ Dey and Engley ${ }^{9}$ previously incorporated lecithin into an antimicrobial neutralization formula for the purposes of counteracting QAC-type sanitizers. Mohammad et al. ${ }^{10}$ reported that the incorporation of soy lecithin at $7.0 \mathrm{~g} / \mathrm{L}$ effectively neutralized CPC $(0.8 \% \mathrm{w} / \mathrm{v})$, facilitating Salmonella detection in a model microbiological medium.

The antimicrobial mechanisms of the sanitizer have been previously suggested to result from the insertion of alkyl chains into microbial membranes, resulting in membrane permeation and cytoplasmic leakage. ${ }^{11,12}$ Nonetheless, studies investigating the mechanisms of CPC antimicrobial activity against Salmonella enterica or other microbial pathogens on poultry carcass or meat surfaces are lacking in the scientific literature. Breen et al. ${ }^{13}$ reported CPC addition reduced or reversed Salmonella cell attachment to chicken skin samples, suggested to result at least partially from electrostatic interactions of the cationic surfactant with anionic headgroups and side groups on the bacterium's outer membrane. Ma et al. ${ }^{14}$ using a CPC-fixing clay for testing antimicrobial activity of CPC against enterotoxigenic E. coli and Salmonella Typhimurium (ST), demonstrated cell morphology disruption by CPC application, as well as respiration inhibition in cells of both pathogens.

In addition to a general lack of data that describe mechanistic interactions of CPC with Salmonella or other human pathogenic bacteria, data are not known to be available detailing the interactions of the pathogenic microbe with the sanitizer CPC when a neutralizing agent such as lecithin is introduced. Understanding the interactions between these three agents would improve food safety specialists' ability to accurately determine the reliability of poultry testing methods for pathogen detection. The objective of this research was to identify the key components of the mechanisms of CPC neutralization by lecithin to yield increased understanding of the interaction of sanitizer and neutralizer, as impacting ST survival. It was hypothesized by researchers that CPC would exert a surfactant-type antimicrobial activity, likely resulting in membrane permeabilization and/or lipopolysaccharide (LPS) release, and that lecithin would neutralize this by counter-acting or inhibiting CPC mixing within bacterial cell membranes.

\footnotetext{
${ }^{1}$ Department of Nutrition and Food Science, Texas A\&M University, College Station, TX 77843-2253, USA; ${ }^{2}$ Artie McFerrin Department of Chemical Engineering, Texas A\&M University, College Station, TX 77843-1136, USA; ${ }^{3}$ Department of Animal Science, Texas A\&M University, College Station, TX 77843-2471, USA; ${ }^{4}$ Present address: Department of Polymer Science and Engineering, Dankook University, 152, Jukjeon-ro, Suji-gu, Yongin-si, Gyeonggi-do 16890, Republic of Korea Correspondence: Mustafa Akbulut (makbulut@tamu.edu) or Thomas Taylor (matt_taylor@tamu.edu)
}

Received: 30 April 2019 Accepted: 13 August 2019

Published online: 16 October 2019 
(a)

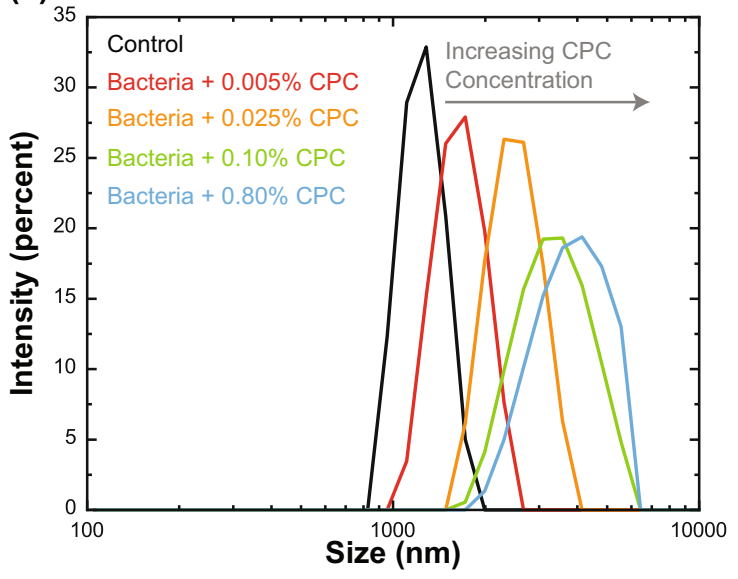

(b)

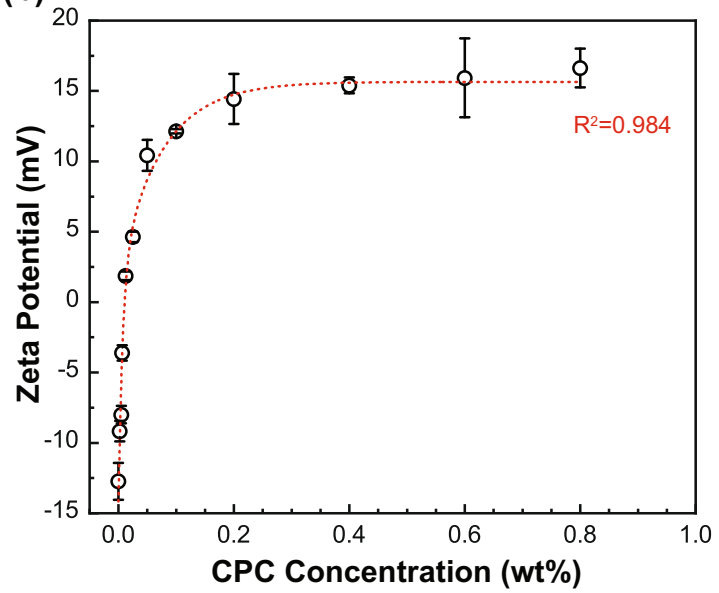

Fig. 1 Hydrodynamic size (intensity averaged) of Salmonella Typhimurium as a function of concentration of CPC (a) obtained by dynamic light scattering and the change in the average $\zeta$-potential $(\mathrm{mV})$ of Salmonella Typhimurium cells with addition of CPC (b). Symbols depict mean values from three independent replications while error bars depict one sample s.d. $(N=3)$. The fitted trend line (dashed) is the two-phase (double) exponential decay model with the coefficient of determination of 0.984
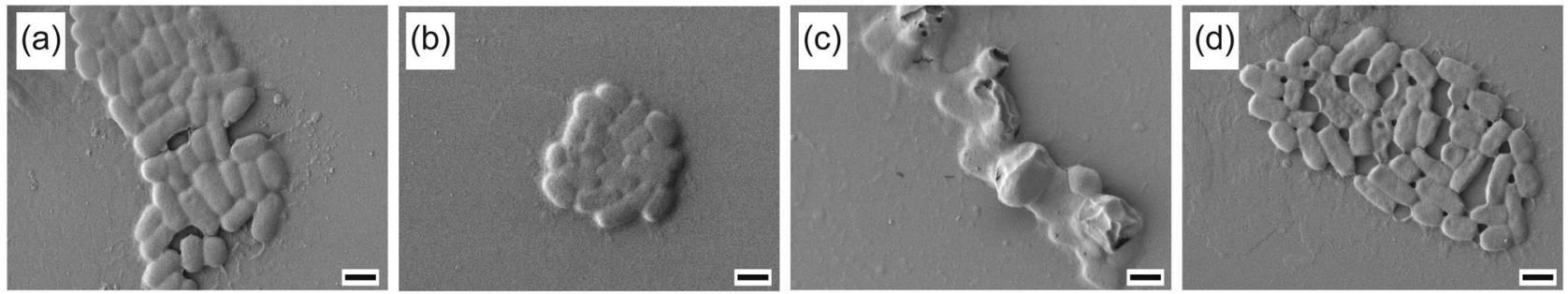

Fig. 2 Scanning electron microscopy (SEM) images for 0.8\% CPC-treated Salmonella Typhimurium cells treated by $0.8 \%$ CPC-treated cells at exposure times of $0 \mathrm{~min}(\mathbf{a}), 1 \mathrm{~min}(\mathbf{b}), 10 \mathrm{~min}(\mathbf{c})$, and $60 \mathrm{~min}(\mathbf{d})$. Images are representative of three independently completed experimental replications completed on differing days. Scale bar is $1 \mu \mathrm{m}$

\section{RESULTS AND DISCUSSION}

Size and $\zeta$-potential of $S$. Typhimurium treated with CPC

Figure 1 a depicts the impact of 0.005 to $0.8 \%$ CPC addition on the resulting sizes of $S$. Typhimurium cells in PBS, inoculated into reaction tubes at $9.1 \pm 0.3 \log _{10} \mathrm{CFU} / \mathrm{ml}$. Untreated (control) ST cells displayed a relatively narrow distribution of size; the mean hydrodynamic radius of non-CPC-treated cells was $1.3 \pm 0.07 \mu \mathrm{m}$ in diameter (Fig. 1a). Addition of $0.8 \%$ CPC destabilized the outer membranes of Salmonella cells, likely the result of combined effects of charge neutralization and surfactant-based membrane lipid re-ordering. The addition of CPC broadened the size distribution of Salmonella cells, producing a wide unimodal distribution with a mean size of $4.0 \pm 1.12 \mu \mathrm{m}$. This would indicate the sanitizer produced aggregation of cells, again likely due to charge neutralization and/or lipid re-ordering and release (Fig. 2). Lipids from Salmonella cell outer membranes were likely released via sanitizer application, resulting in large molecular aggregates of lipid and protein following cell death.

Likewise, mean ל-potential of Salmonella cells not CPC-treated was electro-negative $(-12.73 \pm 1.31 \mathrm{mV}$ ) in PBS (Fig. 1b). After the bacterial cells were treated with different concentrations of $C P C, \zeta-$ potential immediately increased in double exponential fashion. The existence of such a trend is presumably due to the cationic amino groups of CPC and its covering of negatively charged surface components of cell membranes, as well as bacterial aggregation processes. There was a sharp increase observed in samples' $\zeta$-potential upon treatment with up to $0.2 \%$ CPC: a change from $-12.73 \pm 1.31 \mathrm{mV}(0 \% \mathrm{CPC})$ to $+14.43 \pm 1.78 \mathrm{mV}$ (0.2\% CPC) (Fig. 1b). Above $0.2 \%$ CPC, the $\zeta$-potential plateaued, asymptotically increasing to $+16.63 \pm 1.38 \mathrm{mV}$ at $0.8 \%$ CPC. This indicates the full coverage or saturation of negatively charged functional groups on the cell outer surface. This could be due to the reduction of cell surface charge repulsion via covering over of anionic functional groups on the cell's outer membrane, the colloidal stabilization of bacteria or the complexation and bridging of neighboring bacteria walls with oppositely charged CPC. Phosphates and carboxylic acid groups in lipopolysaccharides are responsible for the observed negative zeta potential.

\section{Lecithin addition impacts on CPC-treated Salmonella}

The influence of lecithin on the zeta-potential of $0.8 \%$ CPC-treated ST cells is shown in Fig. 3. Lecithin effect was measured at 0.7, 1.0, 1.5 , and $2.0 \%$ lecithin to determine concentration dependency on observed effects. Lecithin was applied to $0.8 \%$ CPC-treated bacterial cells $(1.0 \mathrm{~min}$ treatment period prior to neutralizer addition) and ( -potential changes measured immediately thereafter. Addition of $1.5-2 \%$ lecithin reduced cationic charge distribution of samples, indicating the capacity of lecithin to neutralize CPC activity.

CPC effect on Salmonella ל-potential with $1.0 \%$ lecithin Non-CPC-exposed ST $\zeta$-potential readings were predictably electro-negative consistently throughout measurements (Fig. 4). Similarly, the neutralizer lecithin was also electro-negative, with a $\zeta$-potential of approximately $-45 \mathrm{mV}$. Samples of ST cells treated with increasing concentrations of CPC displayed increased $\zeta$ potential, up to $11.8-13.6 \mathrm{mV}$, at sufficient concentrations overwhelming the surface charges of ST cells. Surface electrophoretic mobility (ל-potential) of 0.2 or $0.8 \%$ CPC was significantly impacted 
(a)

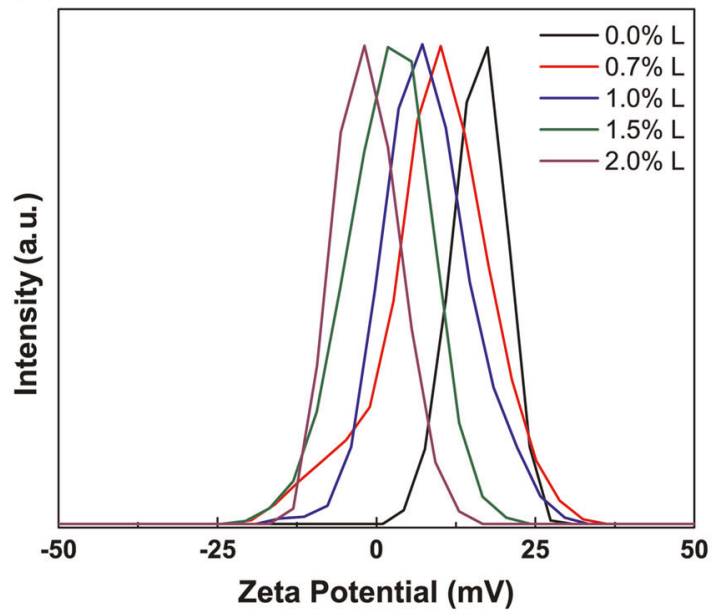

(b)

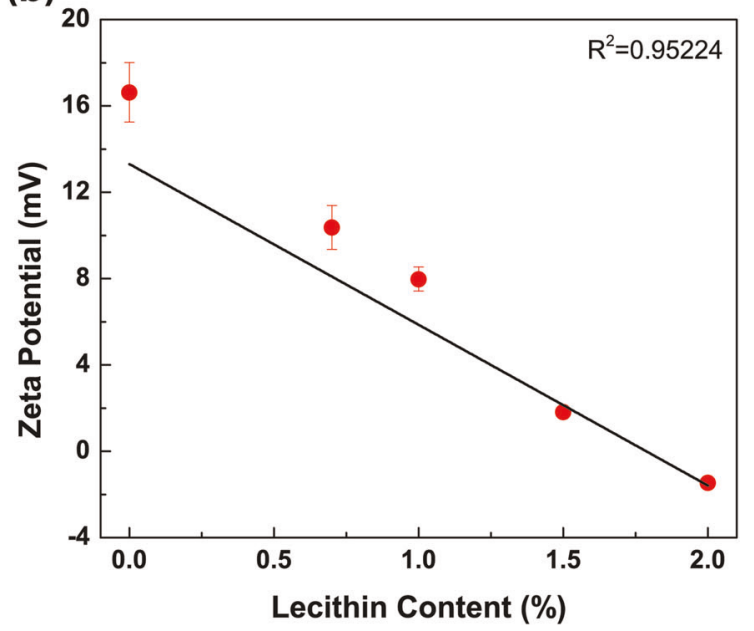

Fig. $3 \zeta$-potential shifts depending on lecithin concentrations (a) and mean $\zeta$-potential of Salmonella Typhimurium cells in the presence of lecithin after $0.8 \%$ CPC treatment. Values in panel (b) represent means of triplicate identical replications; error bars indicate one s.d. Fitted trend line depicts inverse relation of $\zeta$-potential against increased lecithin addition, indicating increasing anionic characteristic of lecithin suspension

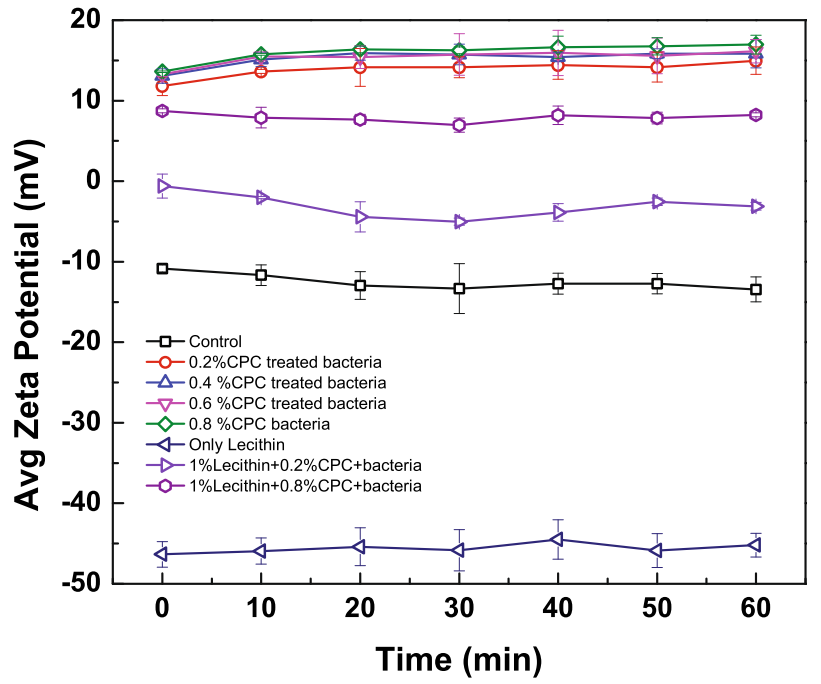

Fig. 4 Change in $\zeta$-potential of Salmonella Typhimurium cells immediately following mixing with CPC and $1.0 \%$ lecithin, over $60 \mathrm{~min}$ holding period at $25^{\circ} \mathrm{C}$. Symbols and connecting lines depict means of triplicate identical replications, while error bars depict one s.d. from sample means

by contact with up to $1.0 \%$ lecithin. The surface potential of a mixture of $0.2 \%$ CPC with $1.0 \%$ lecithin hovered around $0.0 \mathrm{mV}$, whereas $0.8 \%$ CPC with $1 \%$ lecithin $\zeta$-potential ranged between 8.0 and $8.7 \mathrm{mV}$. $\zeta$-potential values for sanitizer and lecithin mixtures increased as sanitizer concentration was increased from 0.2 to $0.8 \%$ (from $11.8 \pm 1.2 \mathrm{mV}$ at $0.2 \% \mathrm{CPC}$ to $13.6 \pm 0.1 \mathrm{mV}$ at $0.8 \%$ CPC at 0 min incubation in sanitizer-treated cells). Mixing of CPC with lecithin effectively negated the anionic charges of lecithin. In comparison, when treated with CPC, the Z-potential of cells treated with $1.0 \%$ lecithin and sanitizer increased in a similar fashion (from $-0.6 \pm 1.5 \mathrm{mV}$ at $0.2 \% \mathrm{CPC}$ in $1.0 \%$ lecithin-treated cells to $8.7 \pm 0.2 \mathrm{mV}$ at $0.8 \% \mathrm{CPC}$ in $1.0 \%$ lecithin-treated cells) (Fig. 4). The increases in $\zeta$-potential in both scenarios may indicate a mechanism of sanitizer activity, that of membrane surface charge disruption, in addition to permeabilization of the microbial membrane to water, ion, and leakage. Addition of lecithin following CPC application onto suspended cells, in reducing the

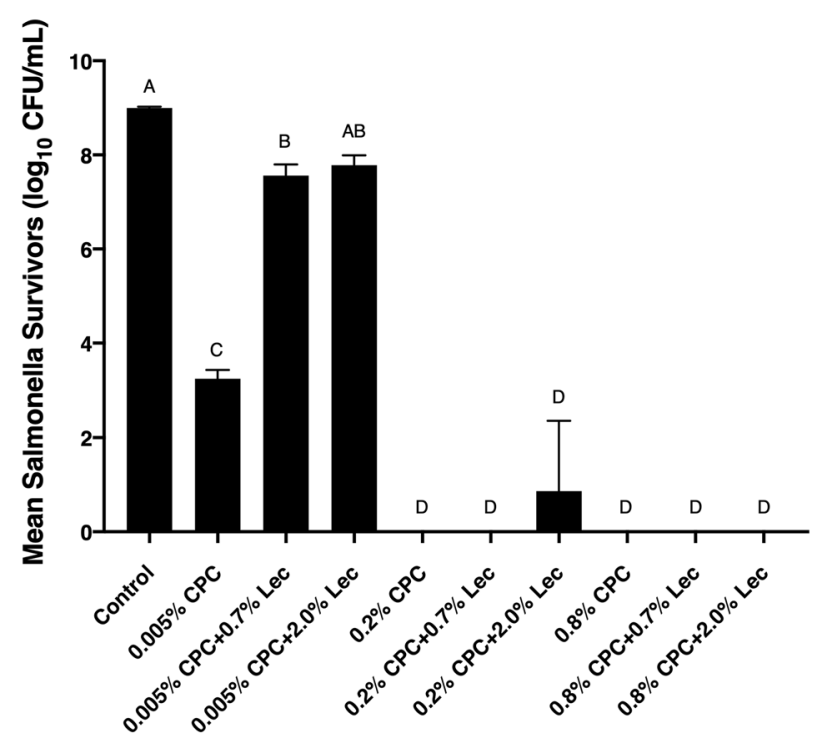

Sanitizer + Neutralizer Treatment

Fig. 5 Least square means of Salmonella Typhimurium counts in presence of increasing CPC concentrations over a $1.0 \mathrm{~min}$ exposure period, with or without 0.7 or $2.0 \%$ Lecithin (Lec) exposure $(40 \mathrm{~min}$ post lecithin incorporation exposure period). Bars depict means from triplicate identically completed replicates; error bars indicate one s.d. from means. Bars labeled with the same letter are not statistically different from each other $(p<0.05)$ by one-way analysis of variance and Tukey's post hoc means separation test

$\zeta$-potential, likely competed with the Salmonella cell membranes for interaction with CPC. CPC possessed strong ability to increase the surface charge of molecules and bacterial cells (Fig. 4), reducing $\mathrm{ST}$ ability to maintain proper respiration and metabolism.

\section{Survival of Salmonella treated with CPC and lecithin}

The dependence of ST survival on CPC concentration, and the concentration of added lecithin, is presented in Fig. 5. The mean count of non-treated control bacteria was $8.99 \pm 0.03 \log _{10}$ CFU/ $\mathrm{mL}$, whereas no detection of ST survivors was achieved for 0.2 or $0.8 \%$ CPC treatments (limit of detection: $1 \mathrm{CFU} / \mathrm{mL}$ ). Interestingly, 
these sanitizer concentrations produced electro-positive $\zeta$-potential values for the bacteria/CPC systems. At $0.005 \%$ CPC treatment, the numbers of $S$. Typhimurium cells decreased from 8.99 to 3.24 $\log _{10} \mathrm{CFU} / \mathrm{mL}$, a $5.76 \log _{10} \mathrm{CFU} / \mathrm{mL}$ reduction. Also at $0.005 \%$ CPC, bacterial survival increased with addition of 0.7 or $2.0 \%$ lecithin, but not in a dose-dependent manner (Fig. 5). Thus, a small content of sanitizer in a liquid buffer led to a statistically significant decrease in the number of Salmonella, indicating a strong correlation between the number of bacteria and CPC treatment $(p<0.05)$. The lack of an apparent dose effect for 0.7 and $2.0 \%$ lecithin at the low concentration of sanitizer, however, indicates the neutralizer was sufficient to provide protection to ST cells, possibly by competing with ST cells for electrostatic interactions between anionic members of lecithin with the cationic surfactant, or by formation of structures wherein lecithin sequestered CPC from ST cells. At higher concentrations of sanitizer (0.2 and $0.8 \%$ ), however, even $2.0 \%$ lecithin was generally unable to overcome the inactivation of the microorganism by the sanitizer. Even though lecithin was added at $1 \mathrm{~min}$ after addition of CPC to ST cells, inactivation of the pathogen occurred quickly, also suggested in Fig. 2. The general lack of pathogen survival at higher CPC doses, even when lecithin was added at higher concentrations, suggests that if a dose effect is to be observed, it will be at a lecithin concentration substantially higher than that approved by the USDA-FSIS in its nBPW formulation $(0.7 \% \mathrm{w} / \mathrm{v})$. Additionally, it may require lecithin to contact Salmonella cells prior to CPC, unlikely to occur given the sequence of sanitizer and neutralizer use in commercial poultry harvest and routine testing.

Hamouda and Baker, Jr. ${ }^{15}$ investigated the antimicrobial mechanism of action of 8N8, a negatively charged water-in-oil emulsion, and W60C, a cationic liposome, against the Gramnegative bacteria Escherichia coli and Vibrio cholerae. Their study demonstrated the positively charged W60C showed much stronger antimicrobial activity than the anionic 8N8 against negatively charged Gram-negative bacteria when divalent cations were chelated. In the current study, we utilized distilled deionized water, reducing the potential for cations to inhibit the attraction of CPC to S. Typhimurium cell surfaces. Interactions between bacteria and cationic and anionic surfactants were also investigated by Zhang et al. ${ }^{16}$ The cationic surfactant, tetraphenylethenedodecyltrimethylammonium bromide (TPE-DTAB), showed high interaction with Escherichia coli by fluorescence microscopy, while the anionic surfactant tetraphenylethene-sodium dodecyl sulfonate (TPE-SDS) did not show any interaction. An electro-positive surface $\zeta$-potential of TPE-DTAB (when in excess versus TPE-SDS) likely resulted in electrostatic attraction to $E$. coli cells membrane surfaces, followed by long alkyl chain of the surfactant inserting into bacterial membrane and producing leakage of cytoplasmic contents. ${ }^{16}$ However, negatively charged TPE-SDS did not attract bacteria and could not come closer to the negatively charged bacteria due to electrostatic repulsion between cell surface and surfactant.

It is important to highlight that at very low concentration $(0.005 \% ; 0.00015 \mathrm{M})), \mathrm{CPC}$ (exposure period of $1.0 \mathrm{~min}$ ) was able to produce a $5.76 \log _{10} \mathrm{CFU} / \mathrm{mL}$ reduction in ST cells in the absence of lecithin, indicating strong potency of CPC as a sanitizer, despite being slightly above the critical micelle concentration (CMC) in water $(0.00012 \mathrm{M}) .^{17}$ Antimicrobial efficacy of sanitizers is impacted by organic load encountered during poultry processing, such as fat and protein content in poultry immersion-type chilling waters. Organic loads in immersion chilling tanks can decrease the efficiency of sanitizers, potentially requiring elevated sanitizer concentrations to overcome inactivation by organic matter. In the current study, aggregation of membrane components of Salmonella was observed when surface charge of suspended bacteria was turned to electro-positive due to the addition of excess CPC, a cationic surfactant.

Impact of CPC and lecithin on cell appearance and morphology In experiments determining the impact of sanitizer with subsequent neutralizer addition to ST cells on cellular shape and morphology changes, micrograph images were collected at 1, 10, and $60 \mathrm{~min}$ following treatment with sanitizer (Fig. 2, Fig. 6a-c). For ST cells treated only by $0.8 \%$ CPC, as the exposure time was increased, sanitizer-treated cells appeared to initially aggregate (Fig. 2b) and membrane lipids emulsify (Fig. 2c), potentially due to surface charges being covered by the cationic surfactant. Salmonella cells lost cell structure during prolonged exposure to the sanitizer (Fig. 2c, d; Fig. 6a-c). Conversely, Fig. 6 panes $d-f$ show embedded bacterial cells and cell matter within a layer of lecithin (added after $1.0 \mathrm{~min}$ CPC application at 0.8\%). SEM images
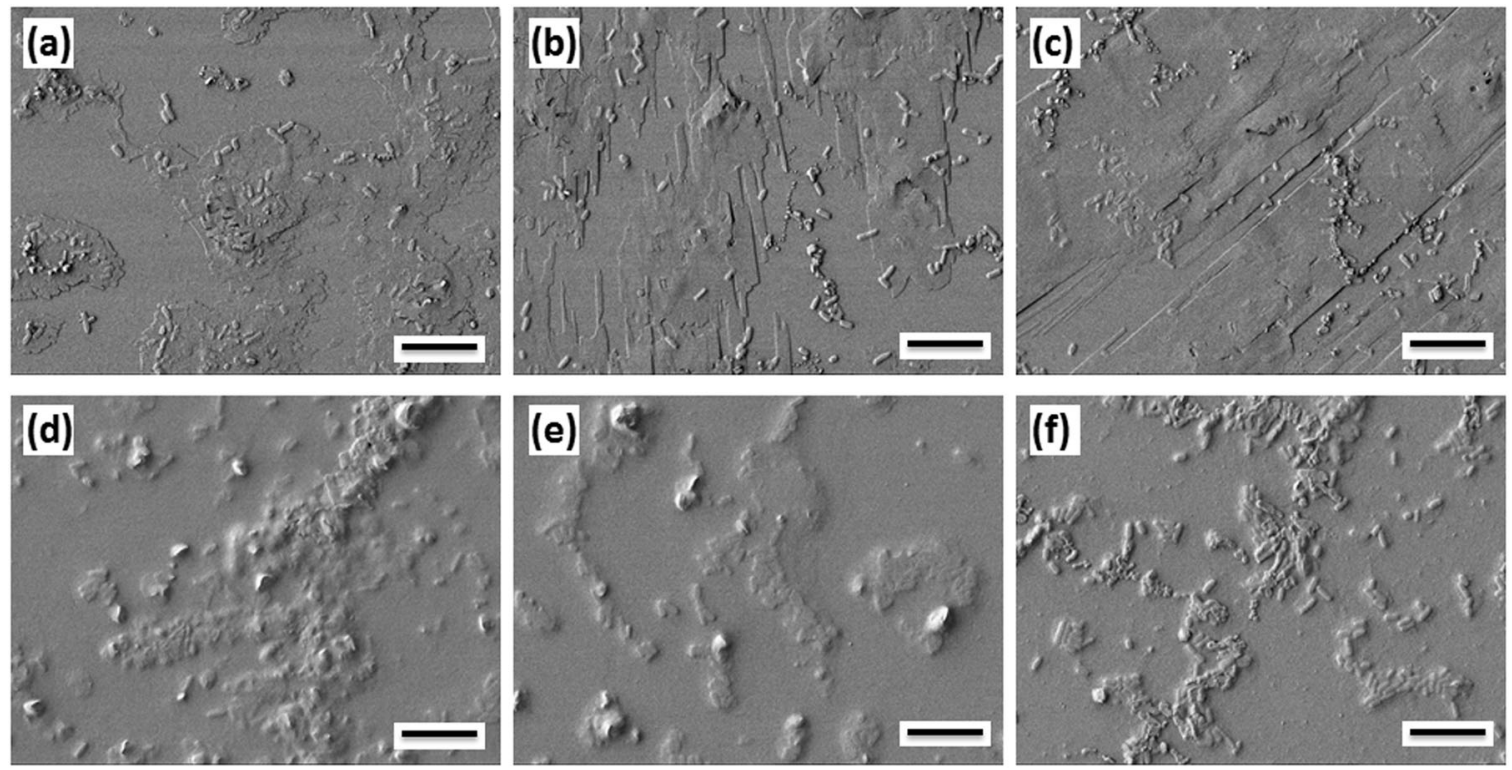

Fig. 6 Scanning electron microscopy (SEM) images (a-c) for 0.8\% CPC-treated Salmonella Typhimurium cells and (d-f) lecithin effect for $0.8 \%$ CPC-treated cells for different exposure times for $1 \mathrm{~min}(\mathbf{a}, \mathbf{d}), 10 \mathrm{~min}(\mathbf{b}, \mathbf{e})$, and $60 \mathrm{~min}(\mathbf{c}, \mathbf{f})$. Images are representative of three independently completed experimental replications completed on differing days. Scale bar is $10 \mu \mathrm{m}$ 
were quite different after lecithin addition as compared to only CPC-treated bacteria. Application of lecithin into the sample vessel resulted in a layer of surfactant forming on the glass slide, covering the remaining cells, and likely furthering emulsification of the membrane lipid components of ST cells. On solid surfaces, addition of lecithin could provide protection to ST cells by covering susceptible membrane components prior to sanitizer insertion, should the neutralizer contact the microbial cell prior to sanitizer contact. This would potentially give rise to increased pathogen survival, as reported in other research detailing neutralization of CPC by lecithin. ${ }^{6}$ In free-swimming cells, such as those which might be found in poultry carcass rinse fluids, addition of lecithin might be expected to form complexes with $\mathrm{CPC}$ rather than forming a protective coating on surface-adhered bacteria, given sufficient content of lecithin. ${ }^{5}$

CPC has been reported effective for reducing the numbers of Salmonella enterica or other bacterial pathogens on surfaces of poultry carcass or cut pieces. ${ }^{2,18}$ Gerba $^{19}$, citing McDonnell ${ }^{20}$, described early steps in quaternary sanitizer antimicrobial mechanisms against bacteria, indicating requirements for attachment and penetration of the outer membrane in Gram-negative bacteria and/or the cytoplasmic membrane in Gram-negative and -positive bacteria, following membrane lipid emulsification and disorganization. However, impacts of the cationic charge component on bacterial surface charge were not discussed. Similarly, other researchers have more recently indicated biscationic QACs demonstrated greater antimicrobial activity against the human enteric pathogen Campylobacter versus monocationic QACs (including $(P C)$. The increased charge of the bis-cationic QACs led to greater pathogen reduction within the experimental period compared to CPC and other monocationic QACs. ${ }^{21}$ On the other hand, research into the influence of CPC treatment on bacterial adherence to oil/water interfaces with the bacterium Pseudomonas fluorescens reported little change in cell membrane hydrophobicity following CPC treatment $(200 \mathrm{mg} / \mathrm{L})$, though cell surface $\zeta$-potential was significantly changed, similar to findings in the current study. ${ }^{22}$ These researchers suggested that influences of the cationic sanitizer on cell surface $\zeta$-potential, specifically charge neutralization through interactions of oppositely charged components, likely led to increased adhesion and interaction with the oil/ water interface. A similar impact was observed here, as changes in cell surface charge of CPC-treated Salmonella were observed, and loss of surface charge led to increased observed membrane lipid components reorganizing and/or aggregating together.

Quisno et al. ${ }^{23}$ reported the inclusion of lecithin as effective for the neutralization of bacteriostatic activity of cationic surfactants and other cationic disinfectants, though no mechanism of activity was suggested. Recent research indicates the inclusion of sanitizer neutralizers, such as lecithin, for the neutralization of quaternary ammonium sanitizers like $C P C$, increases the likelihood of Salmonella recovery during poultry carcass or parts testing. ${ }^{5,24}$ The formation of lecithin/CPC mixed micelles was not detected in the current study by DLS or $\zeta$-potential analysis when mixed with ST cells, though mixing of the surfactants potentially occurred, given changes in $\zeta$-potential for lecithin:CPC mixtures where 1\% lecithin was mixed with CPC at differing concentrations. Microscopy indicated mixing of sanitizer along with bacterial membrane components, likely leading to cell death through cytoplasmic contents leakage via membrane integrity loss.

In the current study, we present hydrodynamic radius, $\zeta-$ potential (electrophoretic mobility), microbiological and microscopic data describing the interactions of the cationic poultry sanitizer CPC with the bacterium ST, with or without the inclusion of the sanitizer neutralizer lecithin. Bacterial cells were reduced to non-detectable counts (from a starting load of $8.99 \pm 0.03 \log _{10}$ $\mathrm{CFU} / \mathrm{ml}$ with a contact time of $1 \mathrm{~min}$ ) at concentrations of CPC of $0.2 \%(2000 \mathrm{ppm})$, but demonstrated sanitizer concentrationdependent survival at very low concentration to the sanitizer
( $0.005 \%$ CPC). Addition of CPC resulted in increased ST ל-potential, likely a result of outer membrane component negative charges being covered by the cationic quaternary amino group in the CPC. These data indicate CPC produces inhibition of the pathogen through initial charge attraction to electro-negative components on the Salmonella surface, and at sufficient concentration, charge neutralization leads to loss of membrane component ordering and organization. The capacity of alkyl chain components on CPC to insert into bacterial membranes was not directly investigated in this study, but possibly added to the observed antimicrobial activity of the sanitizer. Addition of lecithin at up to $2 \%$ potentially provided some degree of neutralization to CPC by competing for charge attraction with Salmonella cells, though plate count data indicate even this concentration of neutralizer was insufficient to afford pathogen survival post-CPC exposure. The use of sanitizer neutralizers during poultry carcass and cut pieces routine sampling has been reported necessary to improve the accuracy of testing for Salmonella and Campylobacter by the USDA-FSIS ${ }^{8}$. In the current study we propose a mechanism of CPC interaction with Salmonella, that being the change in surface charge of treated cells via CPC covered anionic components of the cellular cytoplasmic membrane, resulting in disorganization and membrane integrity loss. Lecithin as a neutralizer, at lower CPC concentrations, competed for electrostatic attraction with CPC and Salmonella membrane components, though at higher concentrations of CPC, lecithin at concentrations used in USDA-FSIS routine testing media was insufficient to neutralize all sanitizer activity via charge neutralization or mixed micelle complex formation, determined by Salmonella inactivation by CPC.

\section{METHODS}

Bacterial isolate preparation

Salmonella enterica serovar Typhimurium (ST) Leeligen Type (LT) 2 was revived from cryo-storage $\left(-80^{\circ} \mathrm{C}\right)$ from the culture collection in the Food Microbiology Laboratory, Department of Animal Science, Texas A\&M Agrilife Research (College Station, TX, USA) by aseptically inoculating a loop of preserved culture into $10.0 \mathrm{~mL}$ steam-sterilized $\left(121^{\circ} \mathrm{C}, 15 \mathrm{~min}\right)$ tryptic soy broth (TSB; Becton, Dickinson and Co., Sparks, MD, USA), and incubating statically for $24 \mathrm{~h}$ at $35^{\circ} \mathrm{C}$. This isolate was chosen to accommodate Texas A\&M University Institutional Biosafety Committee requirements for biosafety level (BSL) 1 containment within microscopy and physico-chemical analytical laboratories within the Artie McFerrin Department of Chemical Engineering, Texas Engineering Experiment Station (College Station, TX, USA). Following $24 \mathrm{~h}$ of incubation, a loopful $(10.0 \mu \mathrm{L})$ of overnight culture was aseptically sub-cultured in $10.0 \mathrm{~mL}$ of sterile TSB and incubated in similar fashion for $24 \mathrm{~h}$ at $35^{\circ} \mathrm{C}$.

\section{Preparation of sanitizer and neutralizer reagents}

Cetylpyridinium chloride (CPC; Cecure $^{\circledR}$ : 40\% active agent per manufacturer guidance) was provided by Safe Foods Corp., N. Little Rock, AR, USA); it was diluted in sterile distilled, deionized water to produce suspensions of $0.2,0.4,0.6$, and $0.8 \%$ CPC for experimentation. Additionally, sterile distilled, deionized water was utilized in order to prepare $0.0 \%$ CPC control samples. Working solutions of the sanitizer were prepared to deliver increasing concentrations of sanitizer; CPC was diluted to produce the concentrations of CPC $(0.002,0.005,0.006,0.013,0.025,0.05,0.1,0.2,0.4$, 0.6 , and $0.8 \%$ ) upon addition to reaction tubes containing bacterial cells. Refined soy lecithin (reagent grade) was purchased from Alfa Aesar (Ward Hill, MA, USA), and was prepared in sterile distilled, deionized water in order to deliver up to $1.0 \%$ lecithin upon mixing with CPC-containing samples, with or without ST cell addition. Lecithin maximal content was chosen based on USDA-FSIS incorporation of $7.0 \mathrm{~g} / \mathrm{L}(0.7 \% \mathrm{w} / \mathrm{v})$ lecithin in the formula of neutralizing buffered peptone water (nBPW) for the rinsing of poultry carcasses and fresh cut pieces. ${ }^{25}$

Light scattering analysis of ST treated by 0.005 to $0.8 \%$ CPC

Revived ST cells were centrifuged at $4000 \mathrm{rpm}$ on a bench-top minicentrifuge for $15 \mathrm{~min}$ at ambient condition $\left(25^{\circ} \mathrm{C}\right)$ to produce a bacterial pellet. Following centrifugation, the supernatant was poured off and cell 
pellets were suspended in one volume of sterile phosphate-buffered saline (PBS; Thermo-Fisher Scientific, Waltham, MA, USA). Three identically completed centrifugation and washing procedures were completed, after which cells were serially diluted in PBS and enumerated on $3 \mathrm{M}^{\mathrm{TM}}$ Petrifilm ${ }^{\mathrm{TM}}$ Aerobic Count Plate films to verify the number of ST cells in the reaction tube were $\sim 9.0 \log _{10} \mathrm{CFU} / \mathrm{mL}$. Inoculated films were incubated $24 \mathrm{~h}$ at $36 \pm$ $1{ }^{\circ} \mathrm{C}$ prior to colony counting. Following enumeration of cells, reaction tubes containing ST cells were mixed with CPC-containing solution prepared to deliver $0.005,0.025,0.1$, or $0.8 \%$ sanitizer upon addition to the culture-containing tube, with a $1 \mathrm{~min}$ exposure period to the sanitizer. Immediately thereafter, cells were loaded into a ZS90 Zetasizer Instrument (Malvern Instruments, Ltd., Westborough, MA, USA) for dynamic light scattering (DLS) analysis of cell size. The measurements were carried out at a scattering angle of $90^{\circ}$ at $25^{\circ} \mathrm{C}$.

\section{ST surface $\zeta$-potential change by CPC and lecithin exposure}

Following initial DLS analysis of ST cells with and without treatment by $0.8 \%$ CPC, analysis was made of the impact of systematically increasing concentrations of CPC $(0.0,0.002,0.005,0.006,0.013,0.025,0.05,0.1,0.2$, $0.4,0.6$, and $0.8 \%$ ) on outer surface $\zeta$-potential (electrophoretic mobility) of ST cells. Cell surface $\zeta$-potential was tracked at multiple time increments over a 60 min period at ambient temperature using a Zeta-Sizer ZS90 Instrument (Malvern Instruments, Ltd.) after bacterial cells were treated with CPC. ST $\zeta$-potential measurements were performed in $0.5 \mathrm{mM}$ PBS $(\mathrm{pH}$ $7.31 \pm 0.02$ ) to minimize the impact of $\mathrm{pH}$ fluctuations. The impact of lecithin inclusion was measured at 2.0, 1.5, 1.0, and $0.7 \%$ lecithin to determine concentration dependency on observed $\zeta$-potential. Lecithin was applied to $0.8 \%$ CPC-treated bacterial cells $(1.0 \mathrm{~min}$ treatment period prior to neutralizer addition) and $\zeta$-potential changes measured immediately thereafter. $\zeta$-potential measurements were collected continuously until stable.

\section{Enumeration of ST cells treated by CPC and lecithin}

ST cells were prepared as described above. Differing concentrations of lecithin $(2.0,0.7$, and $0.0 \%)$ were applied to ST cells pre-exposed for $1.0 \mathrm{~min}$ at ambient temperature condition $\left(25^{\circ}\right)$ to $0.005,0.2$ or $0.8 \%$ CPC (CPC content at which ST cells $\zeta$-potential became constant, intermediate CPC concentration, and maximum allowable CPC concentration allowed for poultry sanitizing, respectively). Following lecithin addition, a $40.0 \mathrm{~min}$ holding period was completed prior to enumeration of surviving bacterial cells. Surviving ST cells were enumerated on tryptic soy agar (TSA; Becton, Dickinson and $\mathrm{Co}$.) following preparation of serial dilutions in phosphatebuffered saline (PBS; Thermo-Fisher Scientific, Waltham, MA, USA) and incubating aerobically for at least $24 \mathrm{~h}$ at $37^{\circ} \mathrm{C}$. Resulting plate counts were $\log _{10}$-transformed for purposes of statistical analysis.

\section{Visualization of CPC and lecithin-treated ST cell morphology}

Microscopic images were obtained by scanning electron microscopy (SEM) using a JSM-7500F electron microscope (JEOL, Tokyo, Japan), in order to visualize any changes in ST cell shape and morphology as a function of sanitizer and lecithin application. The samples were coated with $15 \mathrm{~nm}$ platinum/palladium ( $\mathrm{Pt} / \mathrm{Pd}$ ) to eliminate any positive charging effects. The SEM was operated at an accelerating voltage of $1.0 \mathrm{kV}$ and emission current of $20 \mu \mathrm{A}$. SEM images were taken of Salmonella cells after 1, 10, and 60 min treatment with $0.8 \%$ CPC. After the treatment cells were thoroughly rinsed in sterile milli-Q water to remove CPC residue. Identically prepared ST cells were then subjected to $0.8 \%$ CPC treatment $(1.0 \mathrm{~min})$ and then treated with $0.7 \%$ lecithin, after which micrographs were collected after 1 , 10 , and $60 \mathrm{~min}$ of lecithin exposure.

\section{Data analysis}

All DLS, 乙-potential, and plating (cell enumeration) experiments were replicated three times in identical fashion over differing days $(N=3)$. Additionally, SEM imaging was completed for three identically prepared independent sets of samples over three differing dates. Statistical analysis of data was completed using ORIGIN ${ }^{\circledR}$ v.8 software (OriginLab Corp., Northampton, MA, USA). All microbiological data were $\log _{10}$-transformed prior to statistical analysis. One-way analysis of variance (ANOVA) with Tukey's Honestly Significant Differences (HSD) post hoc test was used to determine significant differences in data between the treatments at a significance level of $P<0.05$.

\section{Reporting summary}

Further information on research design is available in the Nature Research Reporting Summary linked to this article.

\section{DATA AVAILABILITY}

Data will be made available by request to co-senior authors.

\section{ACKNOWLEDGEMENTS}

Disposable reagents and materials were purchased with financial support from Safe Foods Corp., N. Little Rock, AR. Corporate research sponsor had no influence over manuscript development, journal selection and manuscript submission. The open access publishing fees for this article have been covered by the Texas A\&M University Open Access to Knowledge Fund (OAKFund), supported by the University Libraries and the Office of the Vice President for Research.

\section{AUTHOR CONTRIBUTIONS}

Y.Y. and J.K.O. completed all data collection, and participated in development of experimental variables design and data analysis; Y.Y. gave input into manuscript preparation. T.T. and M.A. functioned as co-senior author for development of the manuscript, selection of journal for submission, and approval of manuscript edits in response to reviewers. M.A. supervised data collection by Y.Y. and J.K.O., supervised data analysis, and collaborated on the development and submission of researchsupporting proposal to project sponsor. T.T. led development and submission of research proposal to sponsor, provided oversight on experiments involving microbiological analysis, and collaborated on the development, revision, and submission of the research manuscript.

\section{ADDITIONAL INFORMATION}

Supplementary information accompanies the paper on the npj Science of Food website (https://doi.org/10.1038/s41538-019-0052-x).

Competing interests: The authors declare no competing interests.

Publisher's note Springer Nature remains neutral with regard to jurisdictional claims in published maps and institutional affiliations.

\section{REFERENCES}

1. U.S. Department of Agriculture - Food Safety and Inspection Service. Directive 7120.1, Rev. 49: Safe and suitable ingredients used in the production of meat, poultry, and egg products, https://www.fsis.usda.gov/wps/wcm/connect/ bab10e09-aefa-483b-8be8-809a1f051d4c/7120.1.pdf?MOD=AJPERES (2019).

2. Chen, X. et al. Efficacy of various antimicrobials on reduction of Salmonella and Campylobacter and quality attributes of ground chicken obtained from poultry parts treated in a postchill decontamination tank. J. Food Prot. 77, 1882-1888 (2014).

3. Chylkova, T., Cadena, M., Ferreiro, A. \& Pitesky, M. Susceptibility of Salmonella biofilm and planktonic bacteria to common disinfectant agents used in poultry processing. J. Food Prot. 80, 1072-1079 (2017).

4. Kim, J.-W. \& Slavik, M. F. Cetylpyridinium chloride (CPC) treatment on poultry skin to reduce attached Salmonella. J. Food Prot. 59, 322-326 (1996).

5. Gamble, G. R. et al. Effect of simulated sanitizer carryover on recovery of Salmonella from broiler carcass rinsates. J. Food Prot. 79, 710-714 (2016).

6. Gamble, G. R. et al. Neutralization of bactericidal activity related to antimicrobial carryover in broiler carcass rinse samples. J. Food Prot. 80, 685-691 (2017).

7. U.S. Department of Agriculture - Food Safety and Inspection Service. New performance standards for Salmonella and Campylobacter in not-ready-to-eat comminuted chicken and turkey products and raw chicken parts and changes to related agency verification procedures: response to comments and announcement of implementation schedule. Fed. Regist. 81, 7285-7300 (2016).

8. U.S. Department of Agriculture - Food Safety and Inspection Service. Notice 41-16: New neutralizing buffered peptone water to replace current buffered peptone water for poultry verification sampling, https://www.fsis.usda.gov/wps/wcm/connect/ 2cb982e0-625c-483f-9f50-6f24bc660f33/41-16.pdf?MOD=AJPERES (2016).

9. Dey, B. P. \& Engley, F. B. Jr. Methodology for recovery of chemically treated Staphylococcus aureus with neutralizing medium. Appl. Environ. Microbiol. 45, 1533-1537 (1983).

10. Mohammad, Z. H., Hasan, A. A., Kerth, C. R., Riley, D. G. \& Taylor, T. M. Increased effectiveness of microbiological verification by concentration-dependent 
neutralization of sanitizers used in poultry slaughter and fabrication allowing Salmonella enterica survival. Foods. https://doi.org/10.3390/foods7030032 (2018).

11. Hwang, Y. Y. et al. Antimicrobial activity of nanoemulsion in combination with cetylpyridinium chloride in multidrug-resistant Acinetobacter baumanii. Antimicrob. Agents Chemother. 57, 3568-3575 (2013).

12. Ioannou, C. J., Hanlon, G. W. \& Denyer, S. P. Action of disinfectant quaternary ammonium compounds against Staphylococcus aureus. Antimicrob. Agents Chemother. 51, 296-306 (2007).

13. Breen, P. J. et al. Quaternary ammonium compounds inhibit and reduce the attachment of viable Salmonella typhimurium to poultry tissues. J. Food Sci. 60, 1191-1196 (1995).

14. Ma, Y.-L., Yang, B., Guo, T. \& Xie, L. Antibacterial mechanism of $\mathrm{Cu}^{2+}-\mathrm{ZnO} /$ cetylpyridinium-montmorillonite in vitro. Appl. Clay Sci. 50, 348-353 (2010).

15. Hamouda, T., Baker, J. \& Antimicrobial, J. R. mechanism of action of surfactant lipid preparations in enteric Gram-negative bacilli. J. Appl. Microbiol. 89, 397-403 (2000).

16. Zhang, L., Jiao, L., Zhong, J., Guan, W. \& Lu, C. Lighting up the interactions between bacteria and surfactants with aggregation-induced emission characteristics. Mater. Chem. Front. 2017, 1829-1835 (2017).

17. Bhattarai, A., Yadav, A. K., Sah, S. K. \& Deo, A. Influence of methanol and dimethyl sulfoxide and temperature on the micellization of cetyl pyridinium chloride. $J$. Mol. Liq. 242, 831-837 (2017).

18. Wang, W. C., Li, Y., Slavik, M. F. \& Xiong, H. Trisodium phosphate and cetylpyridinium chloride spraying on chicken skin to reduce attached Salmonella typhimurium. J. Food Prot. 60, $992-994$ (1997).

19. Gerba, C. P. Quaternary ammonium biocides: efficacy in application. Appl. Environ. Microbiol. 81, 464-469 (2015).

20. McDonnell, G. E. Antisepsis, Disinfection, and Sterilization: Types, Action, and Resistance. (ASM Press, 2007).

21. Gunther, N. W., Abdul-Wakeel, A., Reichenberger, E. R., Al-Khalifa, S. \& Minbiole, K. P. C. Quaternary ammonium compounds with multiple cationic moieties
(multaQACs) provide antimicrobial efficacy against Campylobacter jejuni. Food Control 94, 187-194 (2018).

22. Abbasnezhad, H., Gray, M. R. \& Foght, J. M. Two different mechanisms for adhesion of Gram-negative bacterium, Pseudomonas fluorescens LP6a, to an oilwater interface. Col. Surf. B 62, 36-41 (2008).

23. Quisno, R., Gibby, I. W. \& Foter, M. J. A neutralizing medium for evaluating the germicidal potency of the quaternary ammonium salts. Am. J. Pharm. 118, 320-323 (1946).

24. Vuia-Riser, J., Hieke, A.-S. C., Athrey, G., Kerth, C. R. \& Taylor, T. M. Comparison of buffered peptone water to neutralizing buffered peptone water for Salmonella detection from commercially slaughtered whole chicken carcasses and cut chicken parts. Food Prot. Trends 38, 410-420 (2018).

25. U.S. Department of Agriculture - Food Safety and Inspection Service. Neutralizing buffered peptone water (nBPW) in poultry carcass and parts sampling, https:// askfsis.custhelp.com/app/answers/detail/a id/2007/ /neutralizing-bufferedpeptone-water-\%28nbpw\%29-in-poultry-carcass-and-parts-sampling (2016).

(i) Open Access This article is licensed under a Creative Commons Attribution 4.0 International License, which permits use, sharing, adaptation, distribution and reproduction in any medium or format, as long as you give appropriate credit to the original author(s) and the source, provide a link to the Creative Commons license, and indicate if changes were made. The images or other third party material in this article are included in the article's Creative Commons license, unless indicated otherwise in a credit line to the material. If material is not included in the article's Creative Commons license and your intended use is not permitted by statutory regulation or exceeds the permitted use, you will need to obtain permission directly from the copyright holder. To view a copy of this license, visit http://creativecommons. org/licenses/by/4.0/.

(c) The Author(s) 2019 